\title{
Visual imagery in autobiographical memory: The role of repeated retrieval in shifting perspective
}

\author{
Andrew C. Butler ${ }^{\mathrm{a}, *}$, Heather J. Rice ${ }^{\mathrm{b}}$, Cynthia L. Wooldridge ${ }^{\mathrm{c}}$, David C. Rubin ${ }^{\mathrm{d}}$ \\ a University of Texas at Austin, United States \\ ${ }^{\mathrm{b}}$ Washington University in St. Louis, United States \\ ${ }^{\mathrm{c}}$ Washburn University, United States \\ ${ }^{\mathrm{d}}$ Duke University, United States
}

\section{A R T I C L E I N F O}

\section{Article history:}

Received 16 November 2015

Revised 24 February 2016

Accepted 26 March 2016

\section{Keywords:}

Autobiographical memory

Visual imagery

Visual perspective

Retrieval

\begin{abstract}
A B S T R A C T
Recent memories are generally recalled from a first-person perspective whereas older memories are often recalled from a third-person perspective. We investigated how repeated retrieval affects the availability of visual information, and whether it could explain the observed shift in perspective with time. In Experiment 1, participants performed mini-events and nominated memories of recent autobiographical events in response to cue words. Next, they described their memory for each event and rated its phenomenological characteristics. Over the following three weeks, they repeatedly retrieved half of the mini-event and cue-word memories. No instructions were given about how to retrieve the memories. In Experiment 2, participants were asked to adopt either a first- or third-person perspective during retrieval. One month later, participants retrieved all of the memories and again provided phenomenology ratings. When first-person visual details from the event were repeatedly retrieved, this information was retained better and the shift in perspective was slowed.
\end{abstract}

(c) 2016 Elsevier Inc. All rights reserved.

\section{Introduction}

Since the origins of systematic empirical research, visual imagery has been considered a central component of autobiographical memory (Galton, 1883; for reviews see Brewer, 1988; Rubin, 2006). Visual imagery gives rise to a sense of reliving (Rubin, Burt, \& Fifield, 2003) and severe amnesia can result from damage to brain regions that subserve long-term visual memory (Rubin \& Greenberg, 1998; Rubin \& Umanath, 2015). One important aspect of visual imagery is the perspective from which a memory is viewed - individuals report seeing the event through their own eyes for some memories (a first-person or field perspective) and from an external vantage point for other memories (a third-person or observer perspective) (e.g., Freud, 1899/1953; Henri \& Henri, 1896; Nigro \& Neisser, 1983; Rice, 2010). Visual perspective varies greatly across autobiographical memories (Rice \& Rubin, 2011), and it has been linked to a host of diverse phenomena, including emotion (Berntsen \& Rubin, 2006), self-concept (Libby \& Eibach, 2002), depression (Kuyken \& Moulds, 2009), dissociation (Sutin \& Robins, 2010), and post-traumatic stress disorder (PTSD; McIsaac \& Eich, 2004).

The existence of third-person perspective memories presents an interesting puzzle: How do events that are originally experienced from a first-person perspective come to be remembered from a third-person perspective? In the present study,

\footnotetext{
* Corresponding author at: The University of Texas at Austin, Educational Psychology, 1912 Speedway, Stop D5800, Austin, TX 78712-1289, United States. E-mail address: andrewbutler@austin.utexas.edu (A.C. Butler).
} 
we investigated the possibility that the shift in perspective results from a decrease in the availability of visual information from the event (Rice \& Rubin, 2009; Rubin et al., 2003). When visual information from the original event is retained and is more accessible, people may naturally experience the memory from a first-person perspective; however, once visual information is forgotten, the memory for the event may be reconstructed to a greater degree based on general knowledge (Rice \& Rubin, 2009). Before describing our experiments, we briefly review relevant literature on visual perspective and then discuss the potential role of repeated retrieval (i.e., rehearsal) as a mechanism that can either maintain or shift perspective.

\subsection{Visual perspective in autobiographical memories}

The experience of remembering an autobiographical event from a particular perspective necessarily implies the construction of a visual scene that locates the person recalling the memory relative to the memory (Rubin \& Umanath, 2015). Although visual imagery is needed to construct a memory from either a first- or third-person perspective, a greater amount of visual information is required to experience a first-person perspective. In order to construct a memory from a first-person perspective, the person must recall visual details encoded through their eyes and locate themselves in the exact location where they were when the event occurred. In contrast, third-person perspective can be located anywhere relative to the memory, and location varies considerably across memories (Rice \& Rubin, 2011). Given that the person did not encode the event from a third-person perspective, they likely do not have as much visual information available to construct the scene from this perspective. Indeed, memories that are experienced from a first-person perspective are rated as more vivid than those memories experienced from a third-person perspective (Rice \& Rubin, 2009).

The phenomenon of remembering out-of-body experiences during traumatic events provides an example of how visual information is critical to experiencing a first-person perspective. People sometimes report the experience of mentally leaving their body during a traumatic event and observing it from a distance, which some researchers have considered a marker of dissociation (van der Hart, van der Kolk, \& Boon, 1998). An alternative explanation revolves around the limited amount of visual information that is encoded during the traumatic event (see Rubin, Berntsen, \& Bohni, 2008). During highly arousing negative events, people experience a narrowing of attention to focus on the threat, which results in enhanced encoding of central details and impaired encoding of peripheral details (i.e., "tunnel memory"; Berntsen, 2002; Christianson, 1992). With insufficient visual information available to construct the memory from a first-person perspective, memories of the traumatic event are reconstructed from a third-person perspective and interpreted as an out-of-body experience.

Of course, the phenomenon of tunnel memory is an extreme example - more typically, a large amount of visual information is encoded during the course of experiencing an autobiographical event. However, this visual information can become inaccessible over time. The most consistent finding in the visual perspective literature is that recent events are more likely to be recalled from a first-person perspective than older events (McIsaac \& Eich, 2002; Rice \& Rubin, 2009; Robinson \& Swanson, 1993). Given that events are originally experienced from a first-person perspective, this finding has been interpreted as evidence of the reconstructive nature of memory (Freud, 1899/1953; Nigro \& Neisser, 1983). The older the event, the greater the opportunity for mnemonic change to have occurred (e.g., forgetting); as visual information from the original event is lost, then general knowledge is used to reconstruct this aspect of the memory.

Although the loss of visual information may naturally produce third-person perspective memories, people are also capable of intentionally constructing a third-person perspective (Blackmore, 1987; McIsaac \& Eich, 2002). The changes in content and phenomenology that occur when individuals purposefully shift from a first- to third-person perspective during retrieval correspond with the differences observed with naturally occurring first- and third-person perspective memories. For example, when memories are naturally remembered from a first-person perspective, shifting to a third-person perspective results in decreased vividness, sense of reliving, and intensity of emotion (Berntsen \& Rubin, 2006; Robinson \& Swanson, 1993; Williams \& Moulds, 2008). Interestingly, when memories are naturally remembered from a third-person perspective, shifting to a first-person perspective has little or no effect on memory phenomenology. The asymmetry of these findings suggests that the lack of availability of visual information from the original event may be critical to reporting a memory from a third-person perspective.

Given the mnemonic consequences of purposefully shifting from a first- to a third-person perspective, it is no surprise that people often use this cognitive strategy to cope with memories of negative events. For example, individuals with PTSD sometimes report intentionally adopting a third-person perspective in order to avoid reliving the trauma again through their own eyes (McIsaac \& Eich, 2004). The use of third-person perspective as a cognitive avoidance strategy has been documented in other clinical populations as well, such as individuals with depression (Williams \& Moulds, 2007) and chronic pain (McNamara, Benson, McGenny, Brown, \& Albert, 2005). The repeated use of such a strategy over time may lead to the forgetting of visual information, thus hindering the ability to remember the event from a first-person perspective. Indeed, individuals with PTSD or symptomology characteristic of PTSD often naturally remember trauma from a third-person perspective (Berntsen, Willert, \& Rubin, 2003; Porter \& Birt, 2001; Rubin, Boals, \& Berntsen, 2008).

The degree of self-focus during the encoding of an event also affects the visual perspective experienced during subsequent retrieval. Third-person perspective memories are more prevalent for events that induce self-awareness (e.g., public speaking; Nigro \& Neisser, 1983; Rice \& Rubin, 2011) and in individuals who are high on trait self-consciousness (Robinson \& Swanson, 1993). Third-person perspective memories also occur with greater frequency in clinical populations that have mental disorders characterized by abnormal self-focused processing (Wells \& Papageorgiou, 2001), such as agoraphobia (Day, Holmes, \& Hackmann, 2004), body dysmorphic disorder (Osman, Cooper, Hackmann, \& Veale, 2004), and 
obsessive-compulsive disorder (Terry \& Barwick, 1998). When people focus inward during an event, they sometimes construct third-person perspective imagery of how others are viewing their behavior (Clark \& Wells, 1995; Rapee \& Heimberg, 1997). If such imagery is incorporated into the memory of the event and/or its construction detracts from the encoding of first-person perspective visual information during the event, then it would increase the likelihood of naturally experiencing a third-person perspective when subsequently retrieving the memory.

\subsection{Repeated retrieval as a mechanism for both stability and change}

Taken as a whole, the findings from the visual perspective literature suggest several paths by which autobiographical memories come to be naturally remembered from a third-person perspective. We contend that a common thread among these various paths is the availability of visual information from the original event. Furthermore, we hypothesize that repeated retrieval is a potent mechanism that moderates the availability of visual information. Although memory retrieval is often conceptualized as a neutral event, a wealth of research shows that retrieval changes memory (Anderson, Bjork, \& Bjork, 1994; Bjork, 1975; Marsh, 2007; Roediger \& Butler, 2011; Rubin, 1995; St. Jacques \& Schacter, 2013). Critically, repeated retrieval can change memory in two ways: (1) strengthening memory thereby increasing long-term retention; (2) altering memory through the integration of new information and/or selective retrieval of some details but not others.

The effect of repeated retrieval on the availability of visual information likely depends upon why the memory is retrieved. People have different personal and sociocultural goals in thinking about and sharing memories (Marsh, 2007; Pasupathi, 2001). If the first-person visual details from the original event are repeatedly retrieved over time as part of the memory (i.e., a first-person perspective is experienced), then the long-term retention of this information may be increased, thus facilitating the ability to naturally remember the event from a first-person perspective. For example, the repeated retrieval of visual information may help to maintain the exceptional vividness of "flashbulb" memories for unexpected, emotionally intense events (Talarico \& Rubin, 2003). However, if first-person visual details are not consistently retrieved as part of the memory, then this information may be forgotten. For example, repeatedly adopting a third-person perspective as a cognitive avoidance strategy during retrieval may not require first-person visual details in order to construct the memory. As the visual imagery from this alternate perspective is integrated into the memory, the original first-person visual details may become less accessible (McIsaac \& Eich, 2004). Of course, visual information may also be forgotten over time if the memory is not retrieved at all.

\section{Experiment 1}

The primary goal of Experiment 1 was to investigate how repeated retrieval affects the availability of visual information, and thus the visual perspective from which a memory is naturally remembered. The main hypothesis was that repeated retrieval of memories would improve retention of first-person visual details from the original event, thereby helping to maintain first-person visual perspective; correspondingly, without repeated retrieval, these details would become inaccessible and perspective would begin to shift. However, it was unclear to what extent people would retrieve first-person visual details when given minimal instructions about how to remember events, and thus the experiment was somewhat exploratory in nature.

Critically, this primary question of interest cannot be answered by consulting the extant literature. Many researchers invoke repeated retrieval as a causal mechanism in their theoretical explanations of various autobiographical memory phenomena (e.g., Nelson \& Fivush, 2004). However, repeated retrieval is rarely systematically manipulated as an independent variable in studies of autobiographical memory (but see Skowronski, Gibbons, Vogl, \& Walker, 2004; Suengas \& Johnson, 1988). Rather, it is generally measured retrospectively - participants are asked how much they thought or talked about their memories since the event occurred. The findings described above are correlational in nature and thus the direction of causation is unknown. By manipulating retrieval as an independent variable and randomly assigning subjects to conditions in a prospective experiment, the present research provides answers that correlational studies cannot. That is, we can investigate whether varying the nature of repeated retrieval in specific ways can cause the same effects that are observed in more naturalistic situations, while ruling out individual differences factors through random assignment.

A secondary goal of Experiment 1 was to explore the potential for translating findings from controlled laboratory studies on repeated retrieval for practical use with real world autobiographical memories. Studies of autobiographical memory often focus on memories that are created during the course of everyday life. However, in some studies, researchers have participants create memories in the laboratory to gain greater experimental control. For example, one method is to have participants perform a series of manual tasks that involve various sensory and experiential elements (e.g., Mclsaac \& Eich, 2002). One obvious benefit of using lab-created memories is that the original event is documented thereby facilitating the assessment of memory accuracy. Nevertheless, lab-created autobiographical memories differ from real-world autobiographical memories in many potentially important ways (e.g., self-relevance). Thus, we sought to compare these two different methods in order to ascertain whether repeated retrieval produces similar effects on autobiographical memories created inside and outside the laboratory. 


\subsection{Method}

\subsubsection{Participants}

Thirty-two undergraduate students at a medium-sized university participated for course credit or payment.

\subsubsection{Design}

The experiment used a 2 (Type of Memory: cue-word, mini-event) $\times 2$ (Retrieval Activity: retrieval, no retrieval) withinsubjects design.

\subsubsection{Procedure}

In Session 1, participants walked around campus and performed 12 mini events (e.g., separating a deck of cards into 4 suits; see Appendix A for full list). Each mini event was performed in a unique and distinctive location (e.g., the lounge in the psychology building), and the pairing of mini events to locations was the same for all participants. The order of performance was counterbalanced across participants. After returning to the lab, participants nominated 12 recently encoded autobiographical memories using the Galton-Crovitz cueing technique (Crovitz \& Schiffman, 1974). They were presented with 12 cue words (e.g., bird, key; see Appendix A for full list) and instructed to retrieve a memory of a specific event that had occurred in the past 3 weeks for each word. For each cue-word memory, participants provided a label (3-5 words), a description (3-4 sentences), and rated the phenomenological characteristics of their memory on 14 items from the Autobiographical Memory Questionnaire (AMQ; Rubin, Schrauf, \& Greenberg, 2003). Table 1 provides a list of the items, each of which was presented with a rating scale that ranged from 1 to 7 (for full descriptions see Appendix A). The items that measured retrieval (i.e. rehearsal) and visual imagery (see perspective and sensory categories) were included because they are directly relevant to the primary question of interest. The other items that measured recollection, belief, and emotions were also included because they have been linked to visual imagery in previous research, they help to further characterize the richness of the memories being studied, and they inform the comparison between lab-created and real-world memories.

Sessions 2 to 4 were conducted online via a survey website (SurveyMonkey; www.surveymonkey.com). Once a week for the next 3 weeks, participants were sent an email with a link to an online survey. They were prompted to remember half of their cue-word and mini-event memories. The assignment of memories to retrieval activity condition was counterbalanced across participants. For each to-be-recalled memory, they were presented with the label and instructed to remember the event in as much detail as possible. Time stamp information provided by the website was used to ensure that participants took an appropriate amount of time to remember each event.

One month after the initial session, participants returned to the lab for Session 5 . For each of the 12 cue-word and 12 mini-event memories, they viewed the label, attempted to retrieve the memory, and then rated the 14 AMQ items. They were also asked if they successfully retrieved each memory in order to ensure that they could remember the original event.

Table 1

Mean rating given to memories on a 1-7 scale for each AMQ item in Session 1 as a function of Type of Memory (cueword, mini-event) in Experiment 1 (standard deviations in parentheses).

\begin{tabular}{|c|c|c|c|}
\hline AMQ item & Cue-word & Mini-event & $\mathrm{F}(1,31)$ \\
\hline \multicolumn{4}{|l|}{ Retrieval/rehearsal } \\
\hline Thought or talked & $2.5(1.8)$ & $1.6(1.3)$ & $28.77^{* * * *}$ \\
\hline \multicolumn{4}{|l|}{ Perspective } \\
\hline First person/field & $5.6(1.5)$ & $5.9(1.2)$ & $14.13^{* * * *}$ \\
\hline Third person/observer & $2.9(1.9)$ & $2.5(1.8)$ & $7.99^{* * *}$ \\
\hline \multicolumn{4}{|l|}{ Sensory } \\
\hline Visual imagery (see it) & $5.5(1.3)$ & $5.6(1.3)$ & 0.71 \\
\hline Auditory imagery (hear it) & $3.9(1.9)$ & $3.7(2.0)$ & 1.80 \\
\hline \multicolumn{4}{|l|}{ Recollection } \\
\hline Travel back in time & $4.4(1.7)$ & $4.6(1.8)$ & 3.35 \\
\hline Remember/know & $5.5(1.4)$ & $5.8(1.4)$ & $5.46^{*}$ \\
\hline Reliving & $4.6(1.5)$ & $5.1(1.5)$ & $17.25^{* * *}$ \\
\hline \multicolumn{4}{|l|}{ Belief } \\
\hline Real/imagined & $6.0(1.2)$ & $6.2(1.1)$ & $6.92^{*}$ \\
\hline Persuaded wrong & $2.4(1.3)$ & $2.0(1.3)$ & $14.02^{* * *}$ \\
\hline \multicolumn{4}{|l|}{ Emotions } \\
\hline Same strength of emotion & $4.1(1.7)$ & $3.7(1.7)$ & 3.87 \\
\hline Positivity of emotions & $3.3(1.8)$ & $3.4(1.5)$ & 0.18 \\
\hline Negativity of emotions & $3.3(1.9)$ & $2.3(1.4)$ & $27.84^{* * * *}$ \\
\hline Intensity of emotions & $2.9(1.6)$ & $2.3(1.3)$ & $11.09^{* *}$ \\
\hline
\end{tabular}




\subsection{Results}

Participants failed to retrieve $10 \%$ of their memories during the final session (79 of 768 total memories; $M=2.47$ of 24 memories per participant). On average, they failed to retrieve a greater number of cue-word memories $(M=.72)$ than mini-event memories $(M=.52)$; they also failed to retrieve more of the memories assigned to the no retrieval condition $(M=.98)$ than the retrieval condition $(M=.25)$. A $2 \times 2$ repeated measures ANOVA revealed significant main effects of Type of Memory $\left[F(1,31)=4.59, p<.05, \eta_{p}^{2}=.13\right]$ and Retrieval Activity $\left[F(1,31)=21.41, p<.001, \eta_{p}^{2}=.41\right]$; the interaction was not significant $(F<1)$. Although 22 of the 32 participants failed to retrieve one or more memories, every participant successfully retrieved memories assigned to each of four conditions of the $2 \times 2$ design. Thus, events that participants failed to retrieve were excluded from the remaining analyses, but the remainder of each participant's data was included and no participants were excluded entirely. The foregoing analyses were based on means calculated for each participant by averaging scores across memories.

\subsubsection{Initial memories prior to any manipulation in Session 1: Baseline is vivid, first-person perspective memories}

The data for each AMQ item were analyzed with a 2 (Type of Memory) $\times 2$ (Retrieval Activity) repeated measures ANOVA. As expected, because manipulation had yet to be implemented, there was no significant main effect of Retrieval Activity or interaction for any of the items. Table 1 shows the mean rating on each AMQ item in Session 1 for cue-word and mini-event memories (collapsed across retrieval activity condition) as well as the corresponding $F$-value for the main effect of Type of Memory. On average, participants indicated that they had previously retrieved (i.e., "thought or talked about") cue-word memories significantly more than mini-event memories (see first line of Table 1 ). However, ratings of previous retrieval were low for both types of memory, which makes sense given that these memories had been encoded relatively recently.

Ratings of first-person perspective and visual imagery were high, whereas ratings of third-person perspective were low for both types of memories (see Table 1 ). Visual imagery ratings were positively correlated with first-person perspective ratings (cue-word memories: $r=.31, p<.01$; mini-event memories: $r=.25, p<.01$ ), but not with third-person perspective ratings (cue-word memories: $r=-.05$; mini-event memories: $r=-.06$ ). First-person perspective ratings were negatively correlated with third-person perspective ratings (cue-word memories: $r=-.48, p<.01$; mini-event memories: $r=-.47$, $p<.01$ ). On average, participants rated mini-event memories as having significantly more of a first-person perspective and significantly less of a third-person perspective than cue-word memories. However, there was no significant difference in ratings of visual imagery (see Table 1 ).

Although the dependent variables related to visual information were the main interest, ratings of recollection, belief, and emotions were also analyzed (see Table 1). Overall, the ratings suggest a strong feeling of recollection and belief for both types of memories, but relatively little emotion. Several significant differences between the two types of memories emerged: participants' ratings indicated a greater sense of recollection and belief in the accuracy of mini-event memories compared to cue-word memories, but less intensity and negativity of emotion.

\subsubsection{Change between Session 1 and Session 5: Repeated retrieval slows shift from first- to third-person perspective}

For each memory, the change in rating was calculated by subtracting the rating for each AMQ item in Session 1 from the corresponding rating in Session 5. The data for each AMQ item were analyzed with a 2 (Type of Memory) $\times 2$ (Retrieval Activity) repeated measures ANOVA. Table 2 shows the mean change in ratings between Session 1 and Session 5 for each AMQ item as a function of Type of Memory and Retrieval Activity; Table 2 also shows the corresponding F-value for the main effects of Type of Memory and Retrieval Activity as well as the interaction. Focusing on the overall pattern of results from the ANOVA, it is clear that Retrieval Activity (retrieval vs. no retrieval) produced a significant difference in the change in ratings for many of the AMQ items, whereas Type of Memory (cue-word vs. mini-event) had little effect and only one interaction emerged between the two variables.

Confirming that the manipulation had its intended effect, participants rated both types of memories in the repeated retrieval condition as having been significantly more "thought and talked about" than memories in the no retrieval condition (see first line of Table 2). Participants' ratings of first-person perspective and visual imagery decreased from Session 1 to Session 5, while their ratings of third-person perspective generally increased (see Table 2). However, repeated retrieval led to a significantly smaller decrease in the average first-person perspective rating and the average visual imagery rating. With respect to the other AMQ items, participants' ratings of recollection, belief, and emotion generally decreased from Session 1 to Session 5 . Repeated retrieval led to a significantly smaller decrease in ratings of recollection and belief, but it had no effect on the change in ratings for emotion (see Table 2).

\subsection{Discussion}

The results of Experiment 1 clearly support the hypothesis that repeated retrieval can help to maintain the availability of visual information from the original event and slow the shift in visual perspective from first- to third-person. In Session 1, participants reported phenomenology that is characteristic of recently encoded memories: their memories were predominantly viewed from a first-person perspective, rich in visual imagery, and gave rise to a sense of recollection and belief. Over the 3 weeks between Sessions 1 and 5, the phenomenology of these memories changed: the memories began to shift from first- to third-person perspective, visual information was lost, and the sense of recollection and belief diminished. However, 
Table 2

Mean change from Session 1 to Session 5 in ratings on the autobiographical memory questionnaire as a function of Type of Memory and Retrieval Activity in Experiment 1

\begin{tabular}{|c|c|c|c|c|c|c|c|}
\hline \multirow[t]{2}{*}{ AMQ item } & \multicolumn{2}{|c|}{ Cue-word } & \multicolumn{2}{|c|}{ Mini-event } & \multicolumn{3}{|c|}{ ANOVA $F(1,31)$} \\
\hline & $\mathrm{R}$ & NR & $\mathrm{R}$ & NR & Type & Activity & $\mathrm{T} \times \mathrm{A}$ \\
\hline \multicolumn{8}{|l|}{ Retrieval/rehearsal } \\
\hline Thought or Talked & 0.8 & -0.2 & 1.4 & 0.2 & 4.01 & $18.90^{* * *}$ & 0.38 \\
\hline \multicolumn{8}{|l|}{ Perspective } \\
\hline First person/field & -0.4 & -0.9 & -0.3 & -0.9 & 0.28 & $12.77^{*}$ & 0.06 \\
\hline Third person/observer & 0.1 & 0.4 & 0.0 & 0.4 & 0.15 & 3.91 & 0.02 \\
\hline \multicolumn{8}{|l|}{ Sensory } \\
\hline Visual imagery (see it) & -0.5 & -0.8 & -0.4 & -0.7 & 0.14 & $6.81^{*}$ & 0.11 \\
\hline Auditory imagery (hear it) & -0.7 & -0.7 & -0.6 & -1.1 & 1.08 & $6.33^{*}$ & $8.30^{* *}$ \\
\hline \multicolumn{8}{|l|}{ Recollection } \\
\hline Travel back in time & -0.3 & -0.5 & -0.4 & -0.8 & 0.60 & $7.29^{*}$ & 0.62 \\
\hline Remember/know & -0.3 & -0.7 & -0.4 & -0.9 & 1.07 & $6.23^{*}$ & 0.18 \\
\hline Reliving & -0.3 & -0.5 & -0.5 & -1.2 & $4.38^{*}$ & $8.79^{* *}$ & 3.51 \\
\hline \multicolumn{8}{|l|}{ Belief } \\
\hline Real/imagined & -0.3 & -0.4 & -0.4 & -0.7 & 2.12 & 1.35 & 0.77 \\
\hline Persuaded wrong & 0.1 & 0.4 & 0.1 & 0.5 & 0.15 & $11.35^{* *}$ & 0.52 \\
\hline \multicolumn{8}{|l|}{ Emotions } \\
\hline Same strength of emotion & -0.5 & -0.5 & -0.3 & -0.6 & 0.17 & 0.88 & 0.99 \\
\hline Positivity of emotions & -0.1 & -0.1 & -0.3 & -0.5 & $5.28^{*}$ & 1.08 & 0.68 \\
\hline Negativity of emotions & -0.2 & -0.2 & -0.1 & 0.0 & 1.20 & 0.42 & 0.02 \\
\hline Intensity of emotions & -0.1 & -0.1 & -0.3 & -0.2 & 1.11 & 0.13 & 0.01 \\
\hline
\end{tabular}

$\mathrm{R}=$ Retrieval; NR = No Retrieval.

$* p<.05$.

*** $p<.01$.

*** $p<.001$.

memories that were repeatedly retrieved between Sessions 1 and 5 showed less change than memories that were not retrieved during the interim. When participants repeatedly retrieved their memories, they better maintained the firstperson visual perspective and the visual imagery from the original event. Repeated retrieval also helped to maintain a sense of recollection and a belief in the accuracy of the memories.

The retrieval manipulation did not produce a significant difference for third-person perspective ratings, but numerically there was a larger increase in ratings for memories that were not repeatedly retrieved. Although the lack of an increase in third-person perspective ratings that is of equal magnitude to the decrease in first-person perspective ratings may seem unexpected, it is important to note that visual perspective is not a singular construct. First- and third-person perspective ratings are often negatively correlated, but they are better characterized as separate constructs (see Rice \& Rubin, 2009); thus, the pattern of effects for these two variables will not necessarily mirror each other.

\section{Experiment 2}

Experiment 1 showed that repeated retrieval can help to maintain first-person visual perspective and visual information from the original event. However, as discussed in the introduction, the mnemonic effects of repeated retrieval on visual imagery likely depend upon the goal in thinking or talking about the memory (Marsh, 2007; Pasupathi, 2001). For example, individuals with PTSD sometimes adopt a third-person perspective as a cognitive avoidance strategy when recalling their trauma to reduce the emotion and anxiety associated with the memory (McIsaac \& Eich, 2004). In Experiment 1, participants were given minimal instructions on how to retrieve their memories in order to avoid biasing the way that they thought about them. In Experiment 2, we took the opposite approach by instructing participants to repeatedly retrieve their memories from either a first- or third-person perspective. The goal of this manipulation was to examine how repeatedly adopting a particular perspective during retrieval would affect visual imagery as well as the other phenomenological characteristics measured in Experiment 1. We hypothesized that repeatedly retrieving from a first-person perspective would slow the change in visual imagery (as in Experiment 1), whereas repeatedly retrieving from a third-person perspective would not affect the rate of change (or might accelerate it).

In Experiment 2, we also explored the permanency of the mnemonic changes that occur through repeated retrieval. Studies in which people are asked to adopt the opposite of their natural visual perspective show substantial effects on phenomenology when shifting from first- to third-person, but little or no effect of shifting from third- to first-person (Berntsen \& Rubin, 2006; Robinson \& Swanson, 1993; Williams \& Moulds, 2008). The asymmetry of these findings suggests that once visual information from the original event becomes less accessible, it may be difficult to experience the memory from a first-person perspective. In order to investigate this possibility, we added a perspective shift manipulation at the end of the final session in Experiment 2. In the final session, participants first retrieved their memories using whatever perspective came naturally (i.e., they were instructed to disregard prior instructions about retrieving from a first- or third-person 
perspective) and then rated the phenomenology again. Afterwards, they were instructed to retrieve each memory again using the opposite perspective from the one that they had been instructed to adopt during the interim repeated retrieval phase of the experiment. If repeatedly adopting a third-person perspective during retrieval precipitates the loss of firstperson visual details from the original event, then it should be difficult for participants to adopt a first-person perspective. We hypothesized that instructions to shift perspective would produce greater change for memories that were repeatedly retrieved from a first-person perspective relative to a third-person perspective.

\subsection{Method}

\subsubsection{Participants}

Forty undergraduate students at a medium-sized university participated for course credit or payment.

\subsubsection{Design}

The experiment used a 2 (Type of Memory: cue-word, mini-event) $\times 2$ (Retrieval Activity: retrieval, no retrieval) $\times 2$ (Retrieval Perspective: first-person, third-person) mixed design. Type of Memory and Retrieval Activity were manipulated within-subjects while Retrieval Perspective was manipulated between-subjects.

\subsubsection{Procedure}

Table 3 provides an overview of the procedure for Experiment 2. The procedure was the same as in Experiment 1 except for the following changes. First, participants were randomly assigned to a perspective condition at the beginning of the experiment. Second, the number of mini-event and cue-word memories was reduced to decrease the possibility of participants completely forgetting events after the lengthy retention interval. The number of mini-event memories was reduced from 12 to 6 by dropping half of the campus locations and combining pairs of mini-events; that is, each event was made more complex and therefore more memorable by having participants perform two mini-events at each location. The number of cue-word memories was also reduced from 12 to 6 (see Appendix A).

Third, a new phase was added to the end of Session 1 in which participants adopted a particular perspective. After completing the same series of tasks as in Experiment 1, participants were given an explanation about first- and thirdperson perspective and then they were assigned one of the two perspectives while retrieving half of the mini-event and cue-word memories (the other half were not retrieved; i.e. 3 memories in each of the four conditions in the $2 \times 2$ design). After retrieving each memory using the assigned visual perspective, they wrote a description of the event and rated the difficulty of visualizing the event from that perspective on a 7 -point scale $(1=$ extremely easy, $7=$ extremely difficult). The addition of this new phase meant that participants retrieved each memory in the retrieval condition from the assigned perspective four times prior to the final session (once during Session 1 and three times outside of the lab, once each in Sessions 2, 3, and 4).

Fourth, a new phase was added to the end of Session 5 in which participants adopted the opposite perspective from that which they were assigned in Session 1 (for a similar procedure see Berntsen \& Rubin, 2006; Robinson \& Swanson, 1993; Williams \& Moulds, 2008. In Session 5, participants first completed the same series of tasks as in Experiment 1; the retrieval instructions were modified to make clear that they should disregard the previous retrieval instruction to adopt a particular perspective and instead retrieve the memory in whatever way came naturally. After participants had retrieved and re-rated their memories using their natural perspective, they were asked to retrieve all their memories one last time while adopting the opposite perspective from which they were previously assigned. If they had been assigned to repeatedly retrieve from a first-person perspective during the interim between Sessions 1 and 5, then they were asked to adopt a third-person perspective (and vice versa). Thus, each participant adopted the same perspective for all memories during this final phase, including memories in both the retrieval and no retrieval conditions. For each memory, they retrieved the memory, rated perspective using the first- and third-person perspective items from the AMQ, wrote another description of the event, and then rated the difficulty of visualizing the event from that perspective on a 7-point scale.

Table 3

An overview of the procedure for Experiment 2.

\begin{tabular}{ll}
\hline Session & Task \\
\hline 1 & $\begin{array}{l}\text { 1. Perform mini-events and nominate cue-word memories } \\
\text { 2. Retrieve each memory from a natural perspective, write description of event, and rate phenomenology }\end{array}$ \\
& $\begin{array}{l}\text { 3. Retrieve half of mini-events and cue-word memories while adopting either a first- or third-person perspective and write description of } \\
\text { event }\end{array}$ \\
$2-4$ & $\begin{array}{l}\text { 4. Retrieve half of mini-events and cue-word memories while adopting the same perspective assigned in Session } 1 \text { (first- or third-person) } \\
5\end{array}$ \\
$\begin{array}{l}\text { 5. Retrieve each memory from a natural perspective, write description of event, and rate phenomenology } \\
\text { 6. Retrieve each memory while adopting the opposite perspective from that previously assigned, rate perspective, and write description of } \\
\text { event }\end{array}$
\end{tabular}




\subsection{Results}

Participants failed to retrieve their memory for $2.3 \%$ of events (11 out of 480 ) during the final session and there were no significant differences in the number of memories forgotten among the various experimental conditions $(F s<1)$. The few events that participants failed to retrieve during the final session were excluded from the remaining analyses.

\subsubsection{Initial memories prior to any manipulation in Session 1: Initial measures are vivid, first-person perspective memories}

The pattern of ratings in Session 1 largely replicated Experiment 1. Table 4 shows the mean rating on each AMQ item in Session 1 for cue-word and mini-event memories (collapsed across retrieval activity and retrieval perspective conditions) as well as the corresponding $F$-value for the main effect of Type of Memory. The data for each AMQ item were analyzed with a 2 (Type of Memory) $\times 2$ (Retrieval Activity) $\times 2$ (Retrieval Perspective) repeated measures ANOVA. The retrieval activity and perspective manipulations had not yet been implemented at this point, so no significant main effects or interactions were expected for these two variables. With a few exceptions, this expectation held true: the ANOVAs revealed no significant main effects of Retrieval Perspective, one significant main effect of Retrieval Activity, and four significant interactions (see Appendix B). However, there were many significant main effects of Type of Memory.

Participants indicated that they had not previously retrieved (i.e., "thought or talked about") their memories of either type very much, but they had retrieved cue-word memories significantly more than mini-event memories (see first line of Table 4). Participants also gave both types of memories high ratings for first-person perspective and visual imagery, while they gave low ratings for third-person perspective (see Table 4). Visual imagery ratings were positively correlated with firstperson perspective ratings (cue-word memories: $r=.56, p<.01$; mini-event memories: $r=.54, p<.01$ ) and negatively correlated with third-person perspective ratings (cue-word memories: $r=-.22, p<.01$; mini-event memories: $r=-.24, p<.01$ ). First-person perspective ratings were negatively correlated with third-person perspective ratings (cue-word memories: $r=-.58, p<.01$; mini-event memories: $r=-.55, p<.01$ ). Participants rated mini-event memories as having significantly more visual imagery than cue-word memories. They also gave mini-event memories significantly higher first-person perspective ratings than cue-word memories. With respect to third-person perspective, participants gave significantly higher ratings to cue-word memories relative to mini-event memories.

Ratings on the other AMQ items indicated a high degree of recollection and belief for both types of memories, but relatively little emotion. Mini-event memories were rated as having a greater sense of recollection and belief compared to cue-word memories, but less intensity and negativity of emotion (see Table 4).

\subsubsection{Perspective adoption in Session 1: Difficulty adopting a third-person perspective}

At the end of Session 1, participants retrieved the memories assigned to the retrieval conditions while adopting either a first- or third-person perspective. For both types of memories, participants rated adopting a third-person perspective as more difficult $(M=3.8)$ than adopting a first-person perspective $(M=2.3)$. A $2 \times 2$ ANOVA revealed a significant main effect

Table 4

Mean rating given to memories on a 1-7 scale for each AMQ item in Session 1 as a function of Type of Memory (cueword, mini-event) in Experiment 2 (standard deviations in parentheses).

\begin{tabular}{|c|c|c|c|}
\hline AMQ item & Cue-word & Mini-event & $\mathrm{F}(1,38)$ \\
\hline \multicolumn{4}{|l|}{ Retrieval/rehearsal } \\
\hline Thought or Talked & $2.4(1.1)$ & $1.9(1.3)$ & $5.11^{*}$ \\
\hline \multicolumn{4}{|l|}{ Perspective } \\
\hline First person/field & $5.4(1.2)$ & $6.1(0.9)$ & $22.91^{* * *}$ \\
\hline Third person/observer & $2.6(1.2)$ & $2.0(1.2)$ & $16.44^{* * *}$ \\
\hline \multicolumn{4}{|l|}{ Sensory } \\
\hline Visual imagery (see it) & $5.4(0.9)$ & $5.9(0.9)$ & $14.55^{* * *}$ \\
\hline Auditory imagery (hear it) & $3.8(1.5)$ & $3.7(1.8)$ & 0.48 \\
\hline \multicolumn{4}{|l|}{ Recollection } \\
\hline Travel back in time & $4.2(1.5)$ & $4.9(1.5)$ & $27.22^{* * *}$ \\
\hline Remember/know & $5.6(0.9)$ & $6.1(0.9)$ & $16.55^{* * * *}$ \\
\hline Reliving & $4.5(1.3)$ & $5.3(1.2)$ & $39.13^{* * *}$ \\
\hline \multicolumn{4}{|l|}{ Belief } \\
\hline Real/imagined & $5.8(0.8)$ & $6.3(0.8)$ & $24.50^{* * *}$ \\
\hline Persuaded wrong & $2.8(1.1)$ & $2.3(1.0)$ & $14.02^{* * *}$ \\
\hline \multicolumn{4}{|l|}{ Emotions } \\
\hline Same strength of emotion & $3.9(1.2)$ & $4.1(1.3)$ & 2.07 \\
\hline Positivity of emotions & $3.5(1.0)$ & $3.5(1.2)$ & 0.01 \\
\hline Negativity of emotions & $3.1(1.1)$ & $2.4(1.1)$ & $15.06^{* * *}$ \\
\hline Intensity of emotions & $3.0(1.1)$ & $2.6(1.1)$ & $6.50^{*}$ \\
\hline
\end{tabular}


of Retrieval Perspective $\left[F(1,38)=10.66, p<.01, \eta_{p}^{2}=.22\right]$; however, neither the main effect of Type of Memory nor the interaction were significant $(F \mathrm{~s}<1.5)$.

3.2.3. Change between Session 1 and Session 5: "First-person" retrieval slows shift in perspective, "third-person" retrieval precipitates shift

As in Experiment 1, the change in rating on each AMQ item was calculated for each memory. The data for each AMQ item were analyzed with a 2 (Type of Memory) $\times 2$ (Retrieval Activity) $\times 2$ (Retrieval Perspective) repeated measures ANOVA. Table 5 shows the mean change in ratings between Session 1 and Session 5 for each AMQ item as a function of Type of Memory, Retrieval Activity, and Retrieval Perspective; Table 5 also shows the corresponding F-value for the three main effects (six significant interactions were obtained; see below and Appendix B). The overall pattern of results from the ANOVA clearly shows that all three independent variables influenced the change in ratings for various AMQ items, but repeated retrieval had the most widespread effect.

Memories in the repeated retrieval condition were rated as having been "thought and talked about" more than memories in the no retrieval condition (see first line of Table 5), which was expected given the retrieval manipulation. There was also a main effect of Type of Memory: the increase in previous retrieval ratings was greater for mini-event memories relative to cue-word memories $\left[F(1,38)=7.26, p<.01, \eta_{p}^{2}=.16\right]$. Ratings of first-person perspective and visual imagery decreased from Session 1 to Session 5 (see Table 5). The general pattern for both of these items was that repeated retrieval from a firstperson perspective led to a smaller decrease in ratings relative to both repeated retrieval from a third-person perspective and no retrieval. The ANOVA for first-person perspective revealed significant main effects of Retrieval Activity and Retrieval Perspective; however, the interaction between Retrieval Activity and Retrieval Perspective was not significant $\left[F(1,38)=2.41, p=.13, \eta_{p}^{2}=.06\right]$. The ANOVA for visual imagery also showed significant main effects of Retrieval Activity and Retrieval Perspective, as well as a significant interaction between Retrieval Activity and Retrieval Perspective $\left[F(1,38)=5.14, p<.05, \eta_{p}^{2}=.12\right]$. For both of these items, the decrease in ratings was greater for mini-event memories relative to cue-word memories; however, the main effect of Type of Memory was significant for first-person perspective but not visual imagery.

The ratings for third-person perspective showed the opposite pattern - they generally increased from Session 1 to Session 5 (see second item under "Perspective" in Table 5). Repeated retrieval from a third-person perspective led to the largest increases in third-person perspective rating, while no retrieval and repeated retrieval from a first-person perspective led to smaller increases. Significant main effects of Retrieval Activity and Retrieval Perspective were qualified by a significant Retrieval Activity $\times$ Retrieval Perspective interaction $\left[F(1,38)=11.61, p<.01, \eta_{p}^{2}=.23\right]$. Third-person perspective ratings also increased significantly more for mini-event memories relative to cue-word memories.

Table 5

Mean change from Session 1 to Session 5 in ratings on the autobiographical memory questionnaire as a function of Type of Memory, Retrieval Activity, and Retrieval Perspective (i.e. perspective adopted during retrieval in Sessions 1-4) in Experiment 2.

\begin{tabular}{|c|c|c|c|c|c|c|c|c|c|c|c|}
\hline \multirow[t]{3}{*}{ AMQ item } & \multicolumn{4}{|c|}{ First-person perspective } & \multicolumn{4}{|c|}{ Third-person perspective } & \multicolumn{3}{|c|}{ ANOVA $F(1,38)$} \\
\hline & \multicolumn{2}{|c|}{ Cue-word } & \multicolumn{2}{|c|}{ Mini-event } & \multicolumn{2}{|c|}{ Cue-word } & \multicolumn{2}{|c|}{ Mini-event } & \multirow[t]{2}{*}{ Type } & \multirow[t]{2}{*}{ Activity } & \multirow[t]{2}{*}{ Perspective } \\
\hline & $\mathrm{R}$ & NR & $\mathrm{R}$ & NR & $\mathrm{R}$ & NR & $\mathrm{R}$ & NR & & & \\
\hline \multicolumn{12}{|l|}{ Retrieval/rehearsal } \\
\hline Thought or talked & 0.8 & -0.8 & 1.3 & -0.1 & 1.0 & -1.4 & 1.4 & -0.5 & $7.26^{* * *}$ & $32.18^{* * *}$ & 0.34 \\
\hline \multicolumn{12}{|l|}{ Perspective } \\
\hline First person/field & 0.3 & -0.5 & -0.5 & -1.5 & -1.3 & -1.9 & -1.6 & -1.7 & $4.57^{*}$ & $12.13^{* * *}$ & $12.20^{* * *}$ \\
\hline Third person/observer & -0.2 & 0.3 & 0.6 & 0.7 & 1.7 & 0.7 & 2.2 & 1.1 & $6.15^{*}$ & $4.16^{*}$ & $13.48^{* * * *}$ \\
\hline \multicolumn{12}{|l|}{ Sensory } \\
\hline Visual imagery (see it) & 0.1 & -1.0 & -0.4 & -1.2 & -0.9 & -1.3 & -1.4 & -1.4 & 3.70 & $13.28^{* * *}$ & $5.40^{*}$ \\
\hline Auditory imagery (hear it) & -1.0 & -0.9 & -0.6 & -1.2 & -1.1 & -1.6 & -1.1 & -1.5 & 0.03 & $6.84^{*}$ & 1.26 \\
\hline \multicolumn{12}{|l|}{ Recollection } \\
\hline Travel back in time & -0.4 & -0.7 & -0.5 & -1.1 & -1.1 & -1.3 & -1.4 & -1.8 & 3.55 & $7.22^{*}$ & $4.25^{*}$ \\
\hline Remember/know & -0.1 & -0.4 & -0.4 & -1.1 & -0.7 & -1.7 & -0.9 & -1.1 & 1.13 & $12.59^{* * *}$ & $5.00^{*}$ \\
\hline Reliving & -0.2 & -0.9 & -0.6 & -1.8 & -0.8 & -1.7 & -1.4 & -1.6 & $5.23^{*}$ & $15.70^{* * * *}$ & $4.58^{*}$ \\
\hline \multicolumn{12}{|l|}{ Belief } \\
\hline Real/Imagined & -0.2 & -0.5 & -0.2 & -1.2 & -0.2 & -0.7 & -0.7 & -0.8 & $6.55^{*}$ & $4.31^{*}$ & 0.11 \\
\hline Persuaded wrong & -0.1 & 0.5 & -0.2 & 1.1 & 0.1 & 0.8 & 0.3 & 0.9 & 1.52 & $19.30^{* * * * *}$ & 0.60 \\
\hline \multicolumn{12}{|l|}{ Emotions } \\
\hline Same strength of emotion & -0.2 & -1.0 & -1.2 & -1.8 & -0.9 & -1.5 & -1.6 & -1.8 & $12.63^{* * *}$ & $10.19^{* *}$ & 3.20 \\
\hline Positivity of emotions & -0.1 & -0.4 & -0.4 & -0.7 & -0.3 & -1.0 & -0.9 & -0.8 & 2.80 & $5.24^{*}$ & 1.39 \\
\hline Negativity of emotions & -0.4 & -0.1 & -0.3 & -0.2 & -0.5 & -0.8 & -0.7 & -0.6 & 0.01 & 0.29 & 2.28 \\
\hline Intensity of emotions & -0.1 & -0.7 & -0.4 & -0.5 & -0.5 & -0.9 & -0.8 & -0.9 & 0.39 & 6.13 & 2.26 \\
\hline
\end{tabular}

Note: $\mathrm{R}=$ Retrieval; NR = No Retrieval.

${ }^{*} p<.05$.

*** $p<.01$.

*** $p<.001$. 
Focusing on the other AMQ items, ratings of recollection, belief, and emotion generally decreased from Session 1 to Session 5. The pattern of change for items that measure recollection were similar to that for the first-person perspective and visual imagery items - repeated retrieval from a first-person perspective led to less of decrease in recollection ratings relative to both repeated retrieval from a third-person perspective and no retrieval (see items under "Recollection" in Table 5). Repeated retrieval helped to maintain belief regardless of perspective, and also helped to maintain the strength and positivity of emotion (see items under "Belief" and "Emotions" in Table 5).

\subsubsection{Perspective switch in Session 5: Switch to third-person perspective after "first-person" retrieval yields larger changes than} switch to first-person perspective after "third-person" retrieval

After retrieving their memories from a natural perspective in Session 5, participants were asked to switch to the opposite perspective from the one that they had adopted during the repeated retrieval portion of the experiment and then retrieve their memories again. On average, participants gave similar ratings of difficulty regardless of the direction of the switch (third- to first-person or first- to third-person), Type of Memory, and Retrieval Activity condition (grand $M=3.2$ ); the $2 \times 2 \times 2$ ANOVA revealed no significant effects $(F s<1.5)$.

Table 6 shows the mean ratings of first-person and third-person perspective in Phase 1 (natural perspective) and Phase 2 (opposite perspective from that adopted for repeated retrieval) as a function of Type of Memory, Retrieval Activity, and Retrieval Perspective; Table 6 also includes the mean ratings from Session 1 in order to provide context and the change in ratings to facilitate interpretation; the corresponding $F$-value for the three main effects are given as well.

Focusing on the change in ratings from Phase 1 to Phase 2, the data show that the greatest change occurred with participants who had repeatedly retrieved from a first-person perspective and then had to switch to a third-person perspective (see left panel of Fig. 1). In contrast, participants who had repeatedly retrieved from a third-person perspective reported relatively little change when they switched to a first-person perspective (see right panel of Fig. 1 ). A $2 \times 2 \times 2$ ANOVA on the change in first-person perspective ratings showed significant main effects of Retrieval Activity and Retrieval Perspective; the interaction between Retrieval Activity and Retrieval Perspective was not significant $\left[F(1,38)=2.99, p=.09, \eta_{p}^{2}=.07\right]$. A $2 \times 2 \times 2$ ANOVA on the change in third-person perspective ratings showed a significant main effect of perspective; neither the main effect of Retrieval Activity nor the Retrieval Activity $\times$ Retrieval Perspective interaction were significant $\left[F(1,38)=2.34, p=.13, \eta_{p}^{2}=.06\right]$.

\subsection{Discussion}

The results of Experiment 2 provide further support for the hypothesis that repeated retrieval from a first-person perspective can maintain the availability of visual information needed to retrieve a memory from a first-person visual perspective. However, the results also show that repeated retrieval from a third-person perspective can lead to the forgetting of visual information thereby facilitating the shift from first- to third-person perspective. The mnemonic consequences of repeated retrieval depended upon the perspective that participants adopted in retrieving and thinking about their memories.

When participants repeatedly retrieved their memories while adopting a first-person perspective, the results largely replicated Experiment 1. In Session 1, participants retrieved memories that were viewed from a first-person perspective, rich

Table 6

Mean ratings of first-person/field and third-person/observer perspective in Phase 1 (natural perspective) and Phase 2 (opposite perspective from that adopted for repeated retrieval) of Session 5 as a function of Type of Memory, Retrieval Activity, and Retrieval Perspective (i.e. perspective adopted during retrieval in Sessions 1-4) in Experiment 2; mean ratings from Session 1 and the change in ratings across session and phase are also shown.

\begin{tabular}{|c|c|c|c|c|c|c|c|c|c|c|c|}
\hline \multirow[t]{3}{*}{ AMQ item } & \multicolumn{4}{|c|}{ First-person perspective } & \multicolumn{4}{|c|}{ Third-person perspective } & \multicolumn{3}{|c|}{ ANOVA F $(1,38)$} \\
\hline & \multicolumn{2}{|c|}{ Cue-word } & \multicolumn{2}{|c|}{ Mini-event } & \multicolumn{2}{|c|}{ Cue-word } & \multicolumn{2}{|c|}{ Mini-event } & \multirow[t]{2}{*}{ Type } & \multirow[t]{2}{*}{ Activity } & \multirow[t]{2}{*}{ Perspective } \\
\hline & $\mathrm{R}$ & NR & $\mathrm{R}$ & NR & $\mathrm{R}$ & NR & $\mathrm{R}$ & NR & & & \\
\hline \multicolumn{12}{|l|}{ First person/field } \\
\hline Session 1 & 5.3 & 5.1 & 5.7 & 6.1 & 5.9 & 5.6 & 6.2 & 6.3 & $22.91^{* * *}$ & .03 & 3.50 \\
\hline Session 5 Phase 1 & 5.4 & 4.5 & 5.3 & 4.7 & 4.7 & 3.8 & 4.7 & 4.7 & 2.61 & $15.21^{* * *}$ & 1.92 \\
\hline Change (S5P1-S1) & 0.1 & -0.6 & -0.6 & -1.4 & -1.2 & -1.8 & -1.5 & -1.6 & $4.57^{*}$ & $12.13^{* * *}$ & $12.20^{* * *}$ \\
\hline Session 5 phase 2 & 2.8 & 2.8 & 3.0 & 3.0 & 4.8 & 4.5 & 4.9 & 4.7 & 1.97 & .56 & $23.06^{* * *}$ \\
\hline Change (S5P2-S5P1) & -2.6 & -1.7 & -2.3 & -1.7 & 0.1 & 0.7 & 0.2 & 0.0 & 2.59 & $9.58^{* *}$ & $22.88^{* * * *}$ \\
\hline \multicolumn{12}{|l|}{ Third person/observer } \\
\hline Session 1 & 2.6 & 2.7 & 2.2 & 2.0 & 2.3 & 2.8 & 2.0 & 1.9 & $16.44^{* *}$ & .53 & .33 \\
\hline Session 5 Phase 1 & 2.5 & 3.0 & 2.8 & 2.7 & 4.0 & 3.5 & 4.1 & 2.9 & .44 & 3.92 & $4.40^{*}$ \\
\hline Change (S5P1-S1) & -0.1 & 0.3 & 0.6 & 0.7 & 1.7 & 0.7 & 2.1 & 1.0 & $6.15^{*}$ & $4.16^{*}$ & $13.48^{* * * *}$ \\
\hline Session 5 Phase 2 & 5.2 & 5.1 & 5.2 & 4.8 & 3.3 & 2.8 & 3.5 & 2.6 & 1.03 & $6.80^{*}$ & $26.37^{* * *}$ \\
\hline Change (S5P2-S5P1) & 2.7 & 2.1 & 2.2 & 2.1 & -0.7 & -0.7 & -0.6 & -0.3 & .01 & .94 & $59.25^{* * * *}$ \\
\hline
\end{tabular}

Note: $\mathrm{S} 1$ = Session 1; S5P1 = Session 5 Phase 1; S5P2 = Session 5 Phase 2; R = Retrieval; NR = No Retrieval.

$* p<.05$.

** $p<.01$.

*** $p<.001$. 


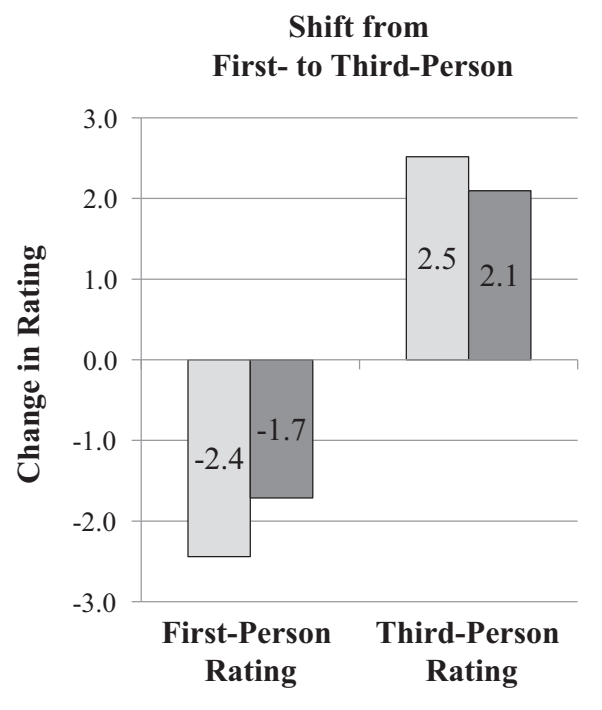

$\square$ Retrieval

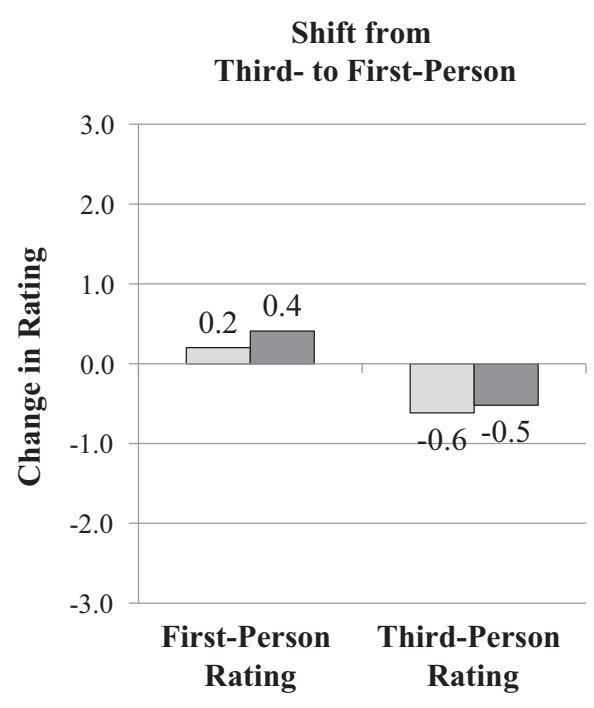

$\square$ No Retrieval

Fig. 1. Mean change in ratings of first-person and third-person perspective from Phase 1 (natural perspective) to Phase 2 (opposite perspective from that adopted for repeated retrieval) of Session 5 as a function of Retrieval Activity in Experiment 2 (data are collapsed across Type of Memory). The left panel shows substantial change for participants who had repeatedly retrieved from a first-person perspective and then switched to a third-person perspective in Phase 2. The right panel shows minimal change for participants who had repeatedly retrieved from a third-person perspective and then switched to a firstperson perspective in Phase 2.

in visual imagery, and gave rise to a sense of recollection and belief. The phenomenology of these memories changed between Sessions 1 and 5: visual perspective shifted from first- towards third-person, visual imagery decreased, and recollection and belief diminished. However, repeated retrieval from a first-person perspective reduced the amount of change that occurred relative to memories that were not retrieved; visual information from the original event, a firstperson perspective, and a sense of recollection and belief were all better maintained.

In contrast, repeated retrieval had the opposite effect when participants adopted a third-person perspective. Repeated retrieval precipitated the shift from first- to third-person perspective relative to memories that were not retrieved; it also led to a similar decrease in visual imagery and recollection compared to memories that were not retrieved. Interestingly, the loss of visual information that produced these changes appeared to be permanent, at least within the context of our experiment. When participants who had repeatedly adopted a third-person perspective were asked to adopt a firstperson perspective, they were unable to re-construct their memory with same degree of first-person visual imagery as they could during Session 1 (see Table 6). In fact, their ratings of perspective showed minimal changes despite their attempt to adopt a first-person visual perspective.

\section{General discussion}

Using a prospective, experimental design, we found that repeated retrieval can either slow or precipitate the shift in visual perspective from first- to third-person. When first-person visual details from the original event were repeatedly retrieved, this information was retained and the shift in visual perspective was slowed or stopped altogether. When the memory was repeatedly retrieved from a third-person perspective (Experiment 2) or the memory was not retrieved over time, visual information was forgotten and a shift in visual perspective was observed. We turn now to discussing the implications of our results within the broader autobiographical memory literature.

\subsection{Repeated retrieval and visual perspective}

By manipulating whether and how memories are repeatedly retrieved, we experimentally replicated many of the correlational findings from the autobiographical memory literature, thereby demonstrating that repeated retrieval can cause these findings. Over the course of a month, we observed a shift in visual perspective from first- towards third-person among memories that were not repeatedly retrieved; this result corresponds nicely with the common finding that older events are more likely to be recalled from a third-person perspective (McIsaac \& Eich, 2002; Rice \& Rubin, 2009; Robinson \& Swanson, 1993). The shift in visual perspective was substantially slowed when first-person visual details from the original event were repeatedly retrieved as part of the memory, which helped to maintain visual imagery and a sense of recollection over time; similarly, many studies have found that the vividness of autobiographical memories is positively correlated with how often 
memories were reported to be rehearsed (e.g., Rubin \& Kozin, 1984; Talarico \& Rubin, 2003). However, when a third-person perspective was adopted during repeated retrieval, it accelerated the shift in visual perspective; correspondingly, among individuals who often adopt a third-person perspective during retrieval, such as those with PTSD (McIsaac \& Eich, 2004) or abnormal self-focused processing (Wells \& Papageorgiou, 2001), there is an increased prevalence of third-person perspective memories (e.g., Berntsen et al., 2003; Day et al., 2004; Porter \& Birt, 2001; Terry \& Barwick, 1998). Finally, once memories had shifted towards third-person perspective, participants could not reconstruct their memories with the same level of visual imagery even when instructed to adopt a first-person perspective; likewise, prior research has shown little or no effect on phenomenology of shifting to a first-person perspective for memories that are naturally recalled from a third-person perspective (Berntsen \& Rubin, 2006; Robinson \& Swanson, 1993; Williams \& Moulds, 2008).

Our findings suggest that there are different paths by which autobiographical memories come to be naturally remembered from third-person perspective; however, a common element underlying many of these paths is the loss of visual information from the original event, and repeated retrieval is a mechanism that moderates this forgetting. That is, we contend that an important source of the variability in visual perspective is produced by differential patterns of retrieval across autobiographical memories. Recent memories tend to be viewed from a first-person perspective, likely because more of the visual information from the original event is available for these memories. The repeated retrieval of first-person visual details as part of a memory increases long-term retention of this information, which means that it will remain available to facilitate retrieval from a first-person perspective even after long periods of time. When a memory is constructed from a different perspective or the memory is not retrieved over long periods of time, first-person visual details are likely to be forgotten; if this visual information becomes unavailable, the memory is reconstructed from a third-person perspective based on general knowledge. In sum, the present research advances our understanding of retrieval as a causal mechanism by experimentally replicating the observation that retrospective judgments of retrieval (i.e., rehearsal) are correlated with changes in perspective.

\subsection{Lab-created vs. real-world memories}

A secondary goal of this research was to examine the generalizability of studies that utilize autobiographical memories that are created in the laboratory. Our results suggest that lab-created memories can be viable analogs for real-world memories. The two types of memories showed similar patterns in phenomenology at baseline in Session 1 (e.g., rich visual imagery, a sense of recollection and belief, etc.) and memory type rarely interacted with the other variables of interest in the two experiments. Given the benefits of using lab-created memories (e.g., greater experimental control, documentation of the original event to assess memory accuracy, etc.), it is encouraging to find evidence that supports the potential for translating findings with such "artificial" tasks to autobiographical memories created outside the laboratory.

Nevertheless, we did find important differences between lab-created memories and real-world memories that suggest the most appropriate type of memory for any given study depends upon the question of interest. For example, cue-word memories were rated as more emotionally intense and negative than the mini-event memories. Thus, if emotion is the construct of interest, real-world memories or a different type of lab-created memory (e.g., watching videos of emotional events) would be more appropriate than the mini-event memories used in this study and others (e.g., McIsaac \& Eich, 2002). The mini-event memories were also rated significantly higher than the cue-word memories on several measures of phenomenology: first-person perspective, visual imagery, recollection, and belief. This difference suggests that at baseline in the present study the cue-word memories had already begun to undergo the changes in phenomenology observed in both types of memories over the month-long retention interval in the experiment (e.g., shifting from first- to third-person perspective). Indeed, despite being less than three-weeks old, the cue-word memories had been thought or talked about significantly more than the mini-event memories. This finding indicates that lab-created memories may be preferable for prospective studies of mnemonic change in autobiographical memories; real-world memories may have changed substantially prior to use in such a study, and they could have reached a stabilized form that is resistant to further change.

\subsection{Limitations and future directions}

One limitation of the present research is the use of autobiographical memories that were relatively mundane and irrelevant to participants' self-concept. Much of autobiographical memory research focuses on understanding memories for events that are highly emotional, consequential to people's lives, and/or important to people's life narrative. Clearly, further research is needed to investigate whether the findings from the present study generalize to these richer, more complex memories. However, it may be difficult to exert experimental control over the retrieval of such memories - if someone experiences a life-altering event, they are likely to think about it frequently regardless of whether they are asked to do so or not. Thus, it makes sense to start with the more mundane memories used in the present study before moving on to more emotional and/or important memories.

Another potential limitation is that the use of instructions to adopt a particular visual perspective during retrieval could have produced demand characteristics. In keeping with prior studies that have dealt with this unavoidable issue (cf. McIsaac \& Eich, 2002), we used relatively simple and brief instructions so as not to unduly influence participants. Even if the instructions did influence participants' ratings of visual perspective, the possibility of demand characteristics cannot explain the related pattern of changes in other aspects of phenomenology. In addition, the best evidence against this potential issue 
is that participants who had repeatedly retrieved their memories from a third-person perspective could not reconstruct their memories with the same visual imagery even when they were explicitly instructed to adopt a first-person perspective.

Given the many areas of psychological research in which visual perspective plays a role (for review see Rice, 2010), the findings of our study have broad implications for understanding how repeated retrieval affects visual imagery. For example, perspective has been identified as an important phenomenological characteristic for several mental disorders, including PTSD, depression, obsessive-compulsive disorder, and phobias. In many of these disorders, individuals repeatedly retrieve or ruminate about events (e.g., the traumatic event experienced in PTSD), thereby maintaining the availability of the visual information and making the memories extremely vivid and emotional (Rubin, Berntsen, \& Bohni, 2008). Understanding the relationship between repeated retrieval and perspective might enable the development of more effective behavioral treatments for these disorders. In conclusion, our findings highlight the need for more prospective studies of autobiographical memory in which retrieval is manipulated as an independent variable. Repeated retrieval is a potent mechanism that can shape the content and phenomenological characteristics of autobiographical memory.

\section{Acknowledgments}

The authors thank Ryan Kruse, Allison Midden, and Chelsea Wiener for their assistance with data collection and coding. While working on this research, the first author (ACB) and the fourth author (DCR) were supported by Grant Numbers F32MH095302 and R01MH066079, respectively, from the National Institute of Mental Health. The content is solely the responsibility of the authors and does not necessarily represent the official views of the National Institute of Mental Health or the National Institutes of Health.

\section{Appendix A}

A list of the mini events, cue words, and Autobiographical Memory Questionnaire items used in Experiments 1 and 2. Mini events

Stretch rubber bands around index cards

Turn to page 56 and read passage out loud from a book

Draw 10 trees on a piece of paper

Separate deck of cards into 4 suits

Stack poker chips in alternating colors

Place several stickers into box with tweezers

Roll dice several times and add up total

Bounce ball with both hands (i.e., first with left hand, then with right)

Cut three stars out of piece of paper

Measure out length of all fingers on one hand

Link 10 paper clips together

Tie eight knots in length of rope

$\underline{\text { Cue words }}$

Bird

Pencil

Bus

Umbrella

Stomach

Window

Pillow

Street

Key

Dirt

Machine

Errand

Note: In Experiment 2, the mini events that are listed next each other were paired to form six more complex mini events. Only the first six cue words were used in Experiment 2. 
Autobiographical Memory Questionnaire Items

Thought or Talked:

Since it happened, I have thought or talked about this event.

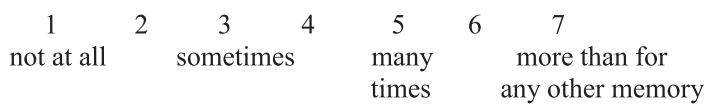

First Person / Field:

When remembering the event, do you see the event through your own eyes?

$\begin{array}{ccccccc}1 & 2 & 3 & 4 & 5 & 6 & \begin{array}{c}7 \\ \text { not at all }\end{array} \\ & & & & & \text { completely }\end{array}$

Third Person / Observer:

When remembering the event, do you see the event as an outside observer?

$\begin{array}{ccccccc}1 & 2 & 3 & 4 & 5 & 6 & \begin{array}{c}7 \\ \text { completely }\end{array}\end{array}$

Visual Imagery (See It):

While remembering the event, I can $\underline{\underline{\text { see }}}$ it in my mind.

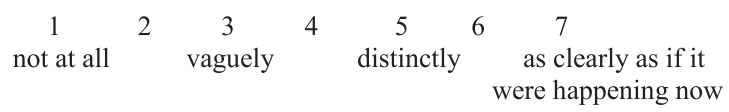

Auditory Imagery (Hear It):

While remembering the event, I can hear it in my mind.

$$
\begin{array}{ccccccc}
1 & 2 & 3 & 4 & 5 & 6 & 7 \\
\text { not at all } & & \text { vaguely } & & \text { distinctly } & \begin{array}{c}
7 \\
\text { as clearly as if it } \\
\text { were happening now }
\end{array}
\end{array}
$$

Travel Back in Time:

While remembering the event, I feel that I travel back to the time when it happened.

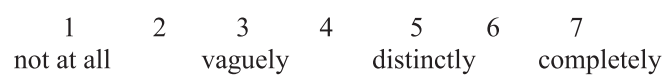

Remember / Know:

As I think about the event, I can actually remember it rather than just knowing that it happened.

$$
\begin{array}{ccccccc}
1 & 2 & 3 & 4 & 5 & 6 & 7 \\
\text { not at all } & & \text { vaguely } & & \text { distinctly } & & \text { completely }
\end{array}
$$

Reliving:

While remembering the event, I feel as though I am reliving it.

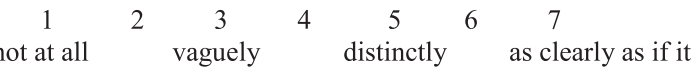

$$
\begin{aligned}
& \text { were happening now }
\end{aligned}
$$


Real / Imagined:

I believe the event in my memory really occurred in the way I remember it and that I have not imagined or fabricated anything that did not occur.

$\begin{array}{lllllll}1 & 2 & 3 & 4 & 5 & 6 & \begin{array}{l}7 \\ 100 \% \\ 100 \%\end{array} \\ \text { imaginary } & & & & & \text { real }\end{array}$

Persuaded Wrong:

If another witness to the event, who you generally trusted, existed and told you a very different account of the event, to what extent could you be persuaded that your memory of the event was wrong.

\begin{tabular}{|c|c|c|c|c|}
\hline $\begin{array}{c}1 \\
\text { not at all }\end{array}$ & 2 & $\begin{array}{c}3 \\
\text { in some } \\
\text { details }\end{array}$ & 4 & $\begin{array}{c}5 \\
\text { in some } \\
\text { main points }\end{array}$ \\
\hline
\end{tabular}

Same Strength of Emotion:

While remembering the event, I feel the emotions as strongly as I did then.

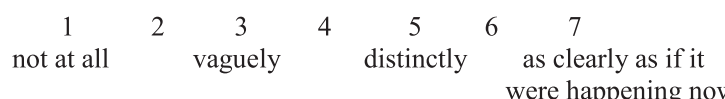

Positivity of Emotions:

While remembering the event, the emotions are extremely positive.

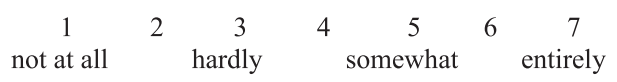

Negativity of Emotions:

While remembering the event, the emotions are extremely negative

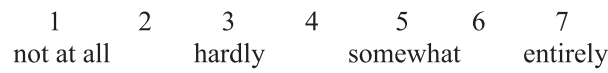

Intensity of Emotions:

The emotions that I feel are extremely intense.

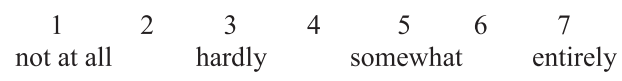

\section{Appendix B}

Additional results from Experiment 2.

\section{Session 1}

The 2 (Type of Memory) $\times 2$ (Retrieval Activity) $\times 2$ (Retrieval Perspective) repeated measures ANOVA on the ratings for each AMQ item in Session 1 revealed a few additional significant interactions. For the item assessing prior retrieval (i.e., "thought or talked about"), there was a significant main effect of Retrieval Activity $\left[F(1,38)=5.08, p<.05, \eta_{p}^{2}=.12\right]$. A significant two-way interaction between Type of Memory and Retrieval Activity $\left[F(1,38)=4.32, p<.05, \eta_{p}^{2}=.10\right]$, and a significant three-way interaction $\left[F(1,38)=5.21, p<.05, \eta_{p}^{2}=.12\right]$. Participants gave higher prior retrieval ratings for cue-word memories in the no retrieval condition $(M=2.7)$ relative to cue-word memories in the retrieval condition $(M=2.2)$, which were both higher than the ratings for mini-event memories in the no retrieval $(M=1.9)$ and retrieval conditions $(M=1.9)$. 
Participants gave mini-event memories significantly higher first-person perspective ratings than cue-word memories, but this result was qualified by a significant interaction between Type of Memory and Retrieval Activity $[F(1,38)=6.83, p<.05$, $\left.\eta_{p}^{2}=.15\right]$. For cue-word memories, participants gave slightly higher first-person perspective ratings in the retrieval condition $(M=5.5)$ relative to the no retrieval condition $(M=5.3)$. For the mini-event memories, they gave slightly lower first-person perspective for ratings in the retrieval condition $(M=6.0)$ relative to the no retrieval condition $(M=6.2)$.

Participants gave significantly higher third-person perspective ratings to cue-word memories relative to mini-event memories, but this main effect was also qualified by a significant Type of Memory $\times$ Retrieval Activity interaction $\left[F(1,38)=4.86, p<.05, \eta_{p}^{2}=.11\right]$. The pattern was the inverse of the first-person perspective interaction: higher thirdperson perspective ratings for cue-word memories in the no retrieval condition $(M=2.8)$ than the retrieval condition $(M=2.5)$, and the opposite direction for ratings for mini-event memories in the retrieval $(M=2.1)$ and no retrieval conditions $(M=2.0)$.

Analysis of the ratings other AMQ items revealed a few additional interactions. A significant interaction between Type of Memory and Retrieval Activity emerged for two items: "travel back in time" $\left[F(1,38)=6.10, p<.05, \eta_{p}^{2}=.14\right]$ and "persuaded wrong" $\left[F(1,38)=4.90, p<.05, \eta_{p}^{2}=.11\right]$. Also, a significant three-way interaction was obtained for two other items: "remember/know" $\left[F(1,38)=5.83, p<.05, \eta_{p}^{2}=.13\right]$ and "positivity of emotions" $\left[F(1,38)=4.35, p<.05, \eta_{p}^{2}=.10\right]$.

\section{Session 2}

The 2 (Type of Memory) $\times 2$ (Retrieval Activity) $\times 2$ (Retrieval Perspective) repeated measures ANOVA on the change in ratings for each AMQ item revealed a few additional significant interactions. For the "remember/know" item, there was a Type of Memory $\times$ Retrieval Perspective interaction $\left[F(1,38)=6.25, p<.05, \eta_{p}^{2}=.14\right]$ and a three-way interaction $\left[F(1,38)=8.89, p<.01, \eta_{p}^{2}=.19\right]$. For the "real/imagined" item, there was an Retrieval Activity $\times$ Retrieval Perspective interaction $\left[F(1,38)=4.31, p<.05, \eta_{p}^{2}=.10\right]$ and a three-way interaction $\left[F(1,38)=4.80, p<.05, \eta_{p}^{2}=.11\right]$.

\section{References}

Anderson, M. C., Bjork, R. A., \& Bjork, E. L. (1994). Remembering can cause forgetting: Retrieval dynamics in long-term memory. Journal of Experimental Psychology: Learning, Memory, and Cognition, 20, 1063-1087.

Berntsen, D. (2002). Tunnel memories for autobiographical events: Central details are remembered more frequently from shocking than from happy experiences. Memory E' Cognition, 30, 1010-1020.

Berntsen, D., \& Rubin, D. C. (2006). Emotion and vantage point in autobiographical memory. Cognition and Emotion, $20,1193-1215$.

Berntsen, D., Willert, M., \& Rubin, D. C. (2003). Splintered memories or vivid landmarks? Qualities and organization of traumatic memories with and without PTSD. Applied Cognitive Psychology, 17, 675-693.

Bjork, R. A. (1975). Retrieval as a memory modifier: An interpretation of negative recency and related phenomena. In R. L. Solso (Ed.), Information processing and cognition (pp. 123-144). New York: Wiley.

Blackmore, S. (1987). Where am I? Perspectives in imagery and the out-of-body experience. Journal of Mental Imagery, 11, 53-66.

Brewer, W. F. (1988). Memory for randomly sampled autobiographical events. In U. Neisser \& E. Winograd (Eds.), Remembering reconsidered: Ecological and traditional approaches to the study of memory (pp. 21-90). Cambridge, England: Cambridge University Press.

Christianson, S. Å. (1992). Emotional stress and eyewitness memory: A critical review. Psychological Bulletin, 112, $284-309$.

Clark, D. M., \& Wells, A. (1995). A cognitive model of social phobia. In R. G. Heimberg, M. R. Liebowitz, D. A. Hope, \& F. R. Schneier (Eds.), Social phobia: Diagnosis, assessment, and treatment (pp. 69-93). New York: The Guilford Press.

Crovitz, H. F., \& Schiffman, H. (1974). Frequency of episodic memories as a function of their age. Bulletin of the Psychonomic Society, 4, 517-518.

Day, S. J., Holmes, E. A., \& Hackmann, A. (2004). Occurrence of imagery and its link with early memories in agoraphobia. Memory, $12,416-427$.

Freud, S. (1899/1953). The complete psychological works of Sigmund Freud (Vol. 3)London: The Hogarth Press Limited.

Galton, F. (1883). Inquiries into human faculty and its development.London: Macmillan.

Henri, V., \& Henri, C. (1896). Enquete sur les premier souvenirs de l'enfance. L'Annee Psychologique, 3, 187-198.

Kuyken, W., \& Moulds, M. L. (2009). Remembering as an observer: How is autobiographical memory retrieval vantage perspective linked to depression? Memory, 17, 624-634.

Libby, L. K., \& Eibach, R. P. (2002). Looking back in time: Self-concept change affects visual perspective in autobiographical memory. Journal of Personality and Social Psychology, 82, 167-179.

Marsh, E. J. (2007). Retelling is not the same as recalling: Implications for memory. Current Directions in Psychological Science, 16, 16-20.

McIsaac, H. K., \& Eich, E. (2002). Vantage point in episodic memory. Psychonomic Bulletin E Review, 9, 146-150.

McIsaac, H. K., \& Eich, E. (2004). Vantage point in traumatic memory. Psychological Science, 15, 248-253.

McNamara, P. M., Benson, E., McGenny, B., Brown, A., \& Albert, M. L. (2005). Modes of remembering in patients with chronic pain: Relation to current pain. Journal of Nervous \& Mental Disease, 193, 53-57.

Nelson, K., \& Fivush, R. (2004). The emergence of autobiographical memory: A social cultural developmental theory. Psychological Review, 111, 486-511.

Nigro, G., \& Neisser, U. (1983). Point of view in personal memories. Cognitive Psychology, 15, 467-482.

Osman, S., Cooper, M., Hackmann, A., \& Veale, D. (2004). Spontaneously occurring images and early memories in people with body dysmorphic disorder. Memory, 12, 428-436.

Pasupathi, M. (2001). The social construction of the personal past and its implications for adult development. Psychological Bulletin, 127, 651-672.

Porter, S., \& Birt, A. R. (2001). Is traumatic memory special? A comparison of traumatic memory characteristics with memory for other emotional life experiences. Applied Cognitive Psychology, 15, S101-S117.

Rapee, R. M., \& Heimberg, R. G. (1997). A cognitive-behavioral model of anxiety in social phobia. Behaviour Research and Therapy, 35, 741-756.

Rice, H. J. (2010). Seeing where we're at: A review of visual perspective and memory retrieval. In J. H. Mace (Ed.), The act of remembering: Toward an understanding of how we recall the past (pp. 228-258). New York: Wiley-Blackwell.

Rice, H. J., \& Rubin, D. C. (2009). I can see it both ways: First- and third-person visual perspectives at retrieval. Consciousness and Cognition, 18, 877-890.

Rice, H. J., \& Rubin, D. C. (2011). Remembering from any angle: The flexibility of visual perspective during retrieval. Consciousness and Cognition, 20, $568-577$.

Robinson, J. A., \& Swanson, K. L. (1993). Field and observer modes of remembering. Memory, 1, 169-184.

Roediger, H. L., III, \& Butler, A. C. (2011). The critical role of retrieval practice in long-term retention. Trends in Cognitive Sciences, $15,20-27$.

Rubin, D. C. (1995). Memory in oral traditions: The cognitive psychology of epic, ballads, and counting-out rhymes.New York: Oxford University Press. 
Rubin, D. C. (2006). The basic-systems model of episodic memory. Perspectives on Psychological Science, 1, $277-311$.

Rubin, D. C., Berntsen, D., \& Bohni, M. K. (2008a). A memory-based model of posttraumatic stress disorder: Evaluating basic assumptions underlying the PTSD diagnosis. Psychological Review, 115, 985-1011.

Rubin, D. C., Boals, A., \& Berntsen, D. (2008b). Memory in posttraumatic stress disorder: Properties of voluntary and involuntary, traumatic and nontraumatic autobiographical memories in people with and without posttraumatic stress disorder symptoms. Journal of Experimental Psychology: General, 137, 591-614.

Rubin, D. C., Burt, C. D. B., \& Fifield, S. J. (2003). Experimental manipulations of the phenomenology of memory. Memory E Cognition, $31,877-886$.

Rubin, D. C., \& Greenberg, D. L. (1998). Visual memory-deficit amnesia: A distinct amnesic presentation and etiology. Proceedings of the National Academy of Sciences of the USA, 95, 5413-5416.

Rubin, D. C., \& Kozin, M. (1984). Vivid memories. Cognition, 16, 81-95.

Rubin, D. C., Schrauf, R. W., \& Greenberg, D. L. (2003). Belief and recollection of autobiographical memories. Memory and Cognition, 31, 877-886.

Rubin, D. C., \& Umanath, S. (2015). Event memory: An evidence-based replacement for episodic memory. Psychological Review, $122,1-23$.

Skowronski, J. J., Gibbons, J. A., Vogl, R. J., \& Walker, W. R. (2004). The effect of social disclosure on the intensity of affect provoked by autobiographical memories. Self and Identity, 3, 285-309.

St. Jacques, P. L., \& Schacter, D. L. (2013). Modifying memory: Selectively enhancing and updating personal memories for a museum tour by reactivating them. Psychological Science, 24, 537-543.

Suengas, A. G., \& Johnson, M. K. (1988). Qualitative effects of rehearsal on memories for perceived and imagined complex events. Journal of Experimental Psychology: General, 117, 377-389.

Sutin, A., \& Robins, R. W. (2010). Correlates and phenomenology of 1st and 3rd person memories. Memory, $18,625-637$.

Talarico, J. M., \& Rubin, D. C. (2003). Confidence, not consistency, characterizes flashbulb memories. Psychological Science, 14, 455-461.

Terry, W. S., \& Barwick, E. C. (1998). Observing-self in memories of obsessive-compulsives. Imagination, Cognition and Personality, $18,59-67$.

van der Hart, O., van der Kolk, B. A., \& Boon, S. (1998). Treatment of dissociative disorders. In J. D. Bremner \& C. R. Marmar (Eds.), Trauma, memory and dissociation (pp. 253-283). Washington, DC: American Psychiatric Press.

Wells, A., \& Papageorgiou, C. (2001). Brief cognitive therapy for social phobia: A case series. Behaviour Research and Therapy, 39, 713-720.

Williams, A. D., \& Moulds, M. L. (2007). Cognitive avoidance of intrusive memories: Recall vantage perspective and associations with depression. Behaviour Research and Therapy, 45, 1141-1153.

Williams, A. D., \& Moulds, M. L. (2008). Manipulating recall vantage perspective of intrusive memories in dysphoria. Memory, 16, 742-750. 